\title{
Inflammatory responses to the occupational inhalation of metal fume
}

\author{
K.T. Palmer*, R. McNeill-Love ${ }^{\#}$, J.R. Poole*, D. Coggon*, A.J. Frew", \\ C.H. Linaker* and J.K. Shute ${ }^{+}$
}

ABSTRACT: Occupational exposure to metal fume promotes a reversible increase in the risk of pneumonia, but by mechanisms which are unclear. To investigate, the current authors measured various markers of host defence function in welders and nonwelders.

Induced sputum and venous blood samples were collected from 27 welders with regular longterm exposure to ferrous metal fume and 31 unexposed matched controls. In sputum, the present authors measured cell counts, the soluble and cellular iron concentration, and levels of interleukin-8, tumour necrosis factor- $\alpha$, myeloperoxidase, matrix metalloproteinase-9, immunoglobulin ( $\mathrm{lg}) \mathrm{A}, \alpha_{2}$-macroglobulin and unsaturated iron-binding capacity. Blood samples were assayed for evidence of neutrophil activation and pneumococcal IgG antibodies.

Welders had significantly higher iron levels and a substantially lower unsaturated iron-binding capacity in their sputum, but, despite a high iron challenge, there was a noteworthy absence of an inflammatory response. Only blood counts of eosinophils and basophils were significantly related to the extent of welding. Weak nonsignificant trends were observed for several other measures, consistent with low-grade priming of neutrophils.

In conclusion, these data suggest that chronic exposure to metal fume blunts responsiveness to inhaled particulate matter. However, the mechanism behind the lack of detectable local inflammatory response requires further investigation.

KEYWORDS: Inflammation, metal fume, occupational, pneumonia, welding

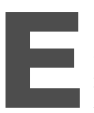
ach year in England and Wales, one person per thousand is admitted to hospital with community-acquired pneumonia (CAP) [1] and four times as many cases are treated outside hospital [2]. Half of cases who are in employment require $>2$ weeks absence from work [3], and case fatality in patients admitted to hospital ranges from $6-24 \%[4,5]$. In subjects aged $<65$ yrs, pneumonia kills as often as all other infectious diseases combined [6].

Some risk factors for CAP are well characterised, including heavy drinking [7], hyposplenism [8], smoking [9] and immunosuppression [10]. An increased risk has also been described in closed communities [11].

Less is known about occupational risk factors, but analyses of mortality in England and Wales have regularly demonstrated a marked excess of deaths from pneumonia in welders [12-14]. A recent analysis [15] showed that the excess is attributable largely to: 1) deaths from lobar pneumonia and pneumonias other than bronchopneumonia; 2) that it is limited to males below retirement age; and 3) that a similar pattern exists for several other occupations entailing exposure to metal fume, such as moulders and coremakers in foundries. In a case-control study of males of working age [16], CAP was associated with occupational exposure to metal fume in the previous year but not in earlier periods, supporting the hypothesis of a hazard that is reversible following cessation of exposure. Risks were highest for recent exposure to ferrous metal fume with lobar pneumonia as the outcome [16].

The health effects of welding have recently been reviewed [17]. The mechanism by which metal fume promotes pneumonia remains unclear. However, it is suggested that submicron-sized particles may have a direct toxic effect on immunocompetence, or that iron may act as a bacterial growth nutrient or agent of oxidative injury [18].

The host response to airway infection is normally to increase the number and activation state of macrophages and neutrophils. This may be

\section{AFFILIATIONS}

*Medical Research Council (MRC) Environmental Epidemiology Unit, -Infection, Inflammation and Repair Division, University of Southampton, Southampton, and

${ }^{+}$School of Pharmacy and Biomedical Sciences, Institute of Biomedical and Biomolecular Sciences, University of Portsmouth, Portsmouth, UK. \#The Royal Naval Hospital, Gibraltar.

CORRESPONDENCE

K. Palmer

MRC Environmental Epidemiology Unit

Southampton General Hospital

Southampton S016 6YD

UK

Fax: 442380704021

E-mail: ktp@mrc.soton.ac.uk

Received:

May 042005

Accepted after revision:

October 192005

SUPPORT STATEMENT

This study was supported by the Worshipful Company of Blacksmiths of the City of London (UK) as a millennium project. 
enhanced by locally produced immunoglobulin (Ig)A [19] that protects the mucosa and is a stimulus for inflammatory cell activation. Typically, inflammatory mediators, such as tumour necrosis factor (TNF)- $\alpha$ and interleukin (IL)-8, or markers of cellular activation, such as matrix metalloproteinase (MMP)-9 and myeloperoxidase (MPO) are elevated during lung infection. According to experimental evidence, several elements of the response to infection, such as neutrophil recruitment and activation, are also triggered by inhaled particulate matter (PM) [20-22]. However, inhaled iron could promote neutrophil death by apoptosis [23, 24], via iron-dependent hydroxyl free radical generation [25], and impair immunocompetence.

To examine the effect of ferrous fume on airways inflammation and host defence, the present authors conducted a study in welders and a matched reference group. The current authors aimed to identify potential biomarkers of the hazard that might subsequently be characterised for their relationship to pneumonia and perhaps be used to assess the relation of risk to levels of occupational exposure. The latter is important for optimal control of the hazard, but, because pneumonia is rare, exposure-response relationships are difficult to establish directly.

Evidence for a generalised inflammatory response was measured as cell counts in blood and sputum, C-reactive protein (CRP) in blood, and TNF- $\alpha$, IL-8, MMP-9, MPO and $\alpha_{2}-$ macroglobulin levels in sputum. Immunocompetence was assessed through the respiratory burst of blood neutrophils, circulating pneumococcal IgG and sputum IgA concentration. With no prior information on the mechanism of predisposition to pneumonia in welders, these measures were chosen $a$ priori from a range of candidates as plausible and convenient starting points for investigation. The current authors also measured iron in the cellular residue and supernatant of sputum and unsaturated iron-binding capacity (UIBC) in sputum as biological indices of recent exposure (past 1-2 months).

\section{MATERIAL AND METHODS Study subjects}

Ethical approval was granted by the UK Defence Medical Services Clinical Research Committee. A total of 27 male volunteers with regular long-term exposure to metal fume as welders were recruited from the civilian workforce at HM Naval Base, Portsmouth, England. These were group-matched by age (in 10-yr bands), social class and smoking status to 31 male volunteers from the same workplace who had no exposure to metal fume in the previous 12 months. All subjects were free from diabetes, asthma, chronic obstructive airways disease and clinically overt immunodeficiency.

\section{Study design and methods}

Subjects were investigated in seven sessions, each conducted towards the end of a normal working week and including similar numbers from exposed and unexposed groups. A nurse-administered questionnaire provided information on matching variables and history of exposure to metal fumes (including metal type, intensity of welding and use of protective equipment). Smoking history and alcohol intake were noted.

A venous blood sample was tested for full blood count, CRP and pneumococcal IgG antibodies. A dichlorofluorescein
(DCFH) oxidation assay was used to measure the polymorphonuclear cell respiratory burst in whole blood [26]. Following incubation at $37^{\circ} \mathrm{C}$ with nonfluorescent $2^{\prime}, 7^{\prime}$-DCFH diacetate and then with phorbol myristate acetate, the amount of the fluorescent derivative DCFH generated by reactive oxygen species was measured by flow cytometry. Neutrophil oxidative burst was expressed as the percentage of neutrophil-produced reactive oxygen metabolites (hydrogen peroxide $\left(\mathrm{H}_{2} \mathrm{O}_{2}\right)$ ), as well as their mean fluorescence intensity (relative amount of $\mathrm{H}_{2} \mathrm{O}_{2}$ produced).

Sputum was induced using a standard protocol [27]. Subjects breathed a nebulised aerosol of $4.5 \%$ saline solution for four consecutive 5-min periods and coughed into a petri dish. Expectorated samples were processed in an equal weight of $6.5 \mathrm{mM}$ Sputolysin ${ }^{\mathrm{TM}}$ (Merck Biosciences, Nottingham, UK), filtered through a $70 \mu \mathrm{m}$ cell strainer, and then separated by centrifugation for $10 \mathrm{~min}$ at $4{ }^{\circ} \mathrm{C}$. The supernatant was stored at $-80^{\circ} \mathrm{C}$. The cell pellet was resuspended in $1 \mathrm{~mL}$ PBS (Invitrogen Ltd, Paisley, UK), mixed thoroughly, and $10 \mu \mathrm{L}$ of the suspension assayed in duplicate for total cell count and percentage viability using Trypan blue stain and a haemocytometer. For differential cell counts, $70 \mu \mathrm{L}$ of a cell suspension $\left(1 \times 10^{6}\right.$ cells $\left.\cdot \mathrm{mL}^{-1}\right)$ was loaded into a cytospin funnel and centrifuged at $21 \times g$ for $5 \mathrm{~min}$. Cytospin slides were air dried and stained with the Hema Gurr Rapid staining set (VWR International, Poole, UK). Slides were fixed in methanol, stained with eosin and air dried again before counterstaining with methylene blue and being washed of excess stain. Slides were air dried and mounted with DPX (VWR International). Differential cell counts were based on $\geqslant 500$ cells $\cdot$ slide $^{-1}$.

Commercially available ELISA or RIA kits were used according to manufacturers' instructions to measure TNF- $\alpha$ (R\&D Systems, Abingdon, UK), IL-8 (Pelikine assay kit, Mast Diagnostics, Liverpool, UK), MPO (Pharmacia \& Upjohn, Uppsala, Sweden) and UIBC (Sigma Diagnostics, Poole, UK). Concentrations of $\alpha_{2}$-macroglobulin and sputum $\operatorname{IgA}$ were measured by an in-house ELISA technique [28]. Total iron in sputum supernatant was measured by electrothermal atomic absorption spectrometry using an Analyst 800 (Perkin Elmer LAS UK Ltd, Beaconfield, UK) following digestion with concentrated nitric acid. Calibration was carried out using aqueous iron standards in the range $0-250 \mu \mathrm{g} \cdot \mathrm{L}^{-1}$. Total iron in the cellular fraction was measured by flame atomic absorption spectrometry (Perkin Elmer 2380 AA; Perkin Elmer LAS UK Ltd) following digestion of the cell pellets in $500 \mu \mathrm{L}$ nitric acid overnight. Calibration was carried out using aqueous iron standards in the concentration range $0-5,000 \mu \mathrm{g} \cdot \mathrm{L}^{-1}$. MMP gelatinase activity was investigated using quantitative substrate gel zymography [29].

All laboratory analyses were performed blind to the exposure status of the participants.

\section{Statistical analysis}

The normality of each variable was assessed using the ShapiroWilk test and, where relevant, improved by a Box-Cox power transformation. A small fixed constant was added to measures that occasionally took the value zero (TNF- $\alpha$, UIBC and epithelial cell count); if frequently zero or undetectable (eosinophils, basophils, lymphocytes and MPO in sputum, 
and eosinophils in blood), Poisson regression analysis was used. For IL-8, the equivalent normal scores were used instead.

Following these adjustments it proved possible to compare levels of biomarkers using standard parametric methods. Independent sample t-tests (unpaired) were used to test the overall relationship of age $(<40$ versus $\geqslant 40 \mathrm{yrs})$, typical alcohol consumption ( $\leqslant 28$ units. week $^{-1}$ versus $>28$ units. week $^{-1}$ ) and smoking status (never, ex- and current) to each of the biological measures. Multiple regression modelling was used to assess their association with welding after adjustment for potential confounders. Welders were also subclassified into high and low exposure groups of roughly equal size according to three criteria: 1) the total iron in the cellular residue of the sputum ( $<$ or $\left.>1.5 \mu \mathrm{g} \cdot \mathrm{L}^{-1}\right)$; or 2 ) their typical duration of weekly welding: $\geqslant 2 \mathrm{~h} \cdot$ day $^{-1}$ for $\geqslant 3$ days $\cdot$ week $^{-1}$ versus less than that (use of fume extraction differed little between groups defined in this way); or 3) years spent as a welder (in two bands, $<10$ yrs or $\geqslant 10$ yrs). Two-sided tests for trend were performed across exposure bands.

\section{RESULTS}

The characteristics of the study participants are presented in table 1 . The exposed group had been employed as professional welders in marine engineering for a median period of $10 \mathrm{yrs}$ (range 6 months to $44 \mathrm{yrs}$ ). Their work entailed welding, burning and cutting, plate fabrication and boilermaking. The majority welded for $>2 \mathrm{~h} \cdot \mathrm{day}^{-1}$ on most working days in a typical working week. A variety of gas-shielded welding techniques were employed (metal inert gas welding, tungsten inert gas welding and metal active gas welding), as well as metal core arc and flux core arc welding. All subjects welded mild steel. In addition, some welded galvanised metal (12), aluminium or aluminium alloys (nine), stainless steel (six), chromium plated metals (two), cast iron (one), brass (one), copper alloys (one), zinc alloys (one) and nickel alloys (one). All welders had welded within the past week and most within $48 \mathrm{~h}$ of being tested.

The nonexposed group comprised fitters and turners (11), project planners, team leaders and engineers (nine), painters (two), crane drivers (two) and miscellaneous trades (seven). They were similar to the exposed group in terms of age, typical weekly alcohol consumption and proportion of ever-smokers (table 1).

In analyses that included all subjects (welders and controls), there were few significant associations between the biological variables and age, alcohol intake and smoking status (data not presented here; supplementary data of the numerous correlations is available at www.erj.ersjournals.com). However, sputum $\alpha_{2}$-macroglobulin and IgA levels tended to be higher in younger adults $(<40$ versus $\geqslant 40$ yrs of age; $\mathrm{p}<0.05)$, pneumococcal IgG titres in blood, and sputum IgA and MMP-9 tended to be higher in heavy drinkers ( $\leqslant 28$ versus $>28$ units week $^{-1}$ of alcohol; $\mathrm{p}<0.05$ ); and blood lymphocyte count and sputum IgA levels were higher in current smokers (versus never-smokers; $\mathrm{p}<0.05$ ). Total iron in the cellular residue was higher, although not significantly, in smokers than nonsmokers. When controls and welders were analysed separately, amongst controls, smokers tended to have higher levels than nonsmokers of MMP-9 (median 602 versus

\begin{tabular}{|c|c|c|}
\hline & Welders & Nonwelders \\
\hline Subjects $n$ & 27 & 31 \\
\hline \multicolumn{3}{|l|}{ Age yrs } \\
\hline All & $32(18-60)$ & $40(20-60)$ \\
\hline$\geqslant 40$ & $10(37)$ & $16(52)$ \\
\hline \multicolumn{3}{|c|}{ Weekly alcohol consumption units } \\
\hline All & $12(0-46)$ & $14(2-61)$ \\
\hline$\geqslant 28$ units & 7 (26) & $7(23)$ \\
\hline \multicolumn{3}{|l|}{ Smoking habits } \\
\hline Current smokers & $10(37)$ & $9(29)$ \\
\hline Ex-smokers & $6(22)$ & $10(32)$ \\
\hline Nonsmokers & $11(41)$ & $12(39)$ \\
\hline \multicolumn{3}{|c|}{ Years employed as welder } \\
\hline All & $10(0.5-44)$ & \\
\hline \multicolumn{3}{|c|}{ Welding in a typical week } \\
\hline$\geqslant 3$ days $\cdot$ week $^{-1}$ & $18(67)$ & \\
\hline$>2 \mathrm{~h} \cdot \mathrm{day}^{-1}$ & $17(63)$ & \\
\hline
\end{tabular}

Data are presented as median (range) or $\mathrm{n}(\%)$

$191 \mathrm{ng} \cdot \mathrm{g}^{-1}$, age- and alcohol-adjusted $\mathrm{p}$-value $\left.=0.08\right), \operatorname{IgA}$ (18.7 versus $7.3 \mu \mathrm{g} \cdot \mathrm{mL}^{-1} ; \mathrm{p}=0.09$ ), and $\alpha_{2}$-macroglobulin (381 versus $\left.126 \mu \mathrm{g} \cdot \mathrm{mL}^{-1} ; \mathrm{p}=0.07\right)$. In welders, by contrast, differences in these variables by smoking status were minor (MMP-9: 278 versus $281 \mathrm{ng} \cdot \mathrm{g}^{-1}, \mathrm{p}=0.92$; $\operatorname{IgA}$ : 20.1 versus $12.5 \mu \mathrm{g} \cdot \mathrm{mL}^{-1}, \quad \mathrm{p}=0.15$; and $\alpha_{2}$-macroglobulin: 184 versus $\left.257 \mu \mathrm{g} \cdot \mathrm{mL}^{-1}, \mathrm{p}=0.96\right)$.

Table 2 compares biomarkers in welders and nonwelders, with regression analyses adjusted for age, smoking and alcohol consumption. As anticipated, exposure to welding fume was associated with significantly higher levels of iron in the sputum, both in the cellular element $(p<0.001)$ and in the supernatant $(p=0.02)$, and there was a significant corresponding reduction in UIBC (mean $2.73 \mu \mathrm{g} \cdot \mathrm{mL}^{-1}$ in welders versus $3.32 \mu \mathrm{g} \cdot \mathrm{mL}^{-1}$ in nonwelders; $\mathrm{p}=0.02$ ). When welders were categorised in two bands, according to the iron levels in the cellular residue of their sputum sample (most and least exposed to iron fume), and compared with nonwelders (unexposed to iron fume), statistically significant trends were observed for total iron in the supernatant (rising values across exposure categories; $\mathrm{p}=0.03$ ) and UIBC (falling values; $\mathrm{p}=0.01)$.

Only a few other significant differences were detected. A greater proportion of welders than nonwelders had elevated blood counts of basophils and eosinophils $(p \leqslant 0.02)$, with some evidence of a trend by exposure level. Weak nonsignificant trends in relation to exposure level were observed for CRP, neutrophil respiratory burst intensity and sputum IgA (higher in exposed categories); and for eosinophils in sputum (lower in exposed categories). Levels of pneumococcal antibodies in blood and $\alpha_{2}$-macroglobulin and MPO in sputum tended to be higher, and IL- 8 in sputum lower, in welders relative to the unexposed comparison group, but not significantly and without apparent trend by exposure level. Most differences were small in absolute terms. The proportion of viable cells in 
TABLE 2 Comparison of inflammatory and immunological measures between welders and nonwelders

\begin{tabular}{|c|c|c|c|c|c|c|}
\hline & \multirow[t]{2}{*}{ Nonwelders } & \multicolumn{3}{|c|}{ Welders: iron in cellular residue } & \multicolumn{2}{|c|}{ p-value ${ }^{\#}$} \\
\hline & & $\leqslant 1.5 \mu \mathrm{g} \cdot \mathrm{L}^{-1}$ & $>1.5 \mu \mathrm{g} \cdot \mathrm{L}^{-1}$ & All & $\begin{array}{l}\text { Welders versus } \\
\text { nonwelders }\end{array}$ & $\begin{array}{c}\text { Test for } \\
\text { trend }\end{array}$ \\
\hline \multicolumn{7}{|l|}{ Inflammatory markers in blood } \\
\hline Neutrophils $10^{9}$ cells $\cdot \mathrm{L}^{-1}$ & $3.3(31)$ & $3.6(13)$ & $3.1(14)$ & $3.3(27)$ & 0.99 & 0.73 \\
\hline Eosinophils $10^{9}$ cells $\cdot L^{-1}$ & $0.1,33 \% \geqslant 0.2(30)$ & $0.3,62 \% \geqslant 0.2(13)$ & $0.2,71 \% \geqslant 0.2(14)$ & $0.2,67 \% \geqslant 0.2(27)$ & 0.01 & 0.09 \\
\hline Basophils $10^{9}$ cells $\cdot L^{-1}$ & $0.1,17 \% \geqslant 0.2(30)$ & $0.1,31 \% \geqslant 0.2(13)$ & $0.2,71 \% \geqslant 0.2(14)$ & $0.2,52 \% \geqslant 0.2(27)$ & 0.02 & 0.04 \\
\hline White blood cells $10^{9}$ cells $\cdot L^{-1}$ & $6.0(31)$ & $6.5(13)$ & $5.5(14)$ & $5.9(27)$ & 0.77 & 0.37 \\
\hline C-reactive protein ${ }^{\curvearrowleft} \mathrm{mg} \cdot \mathrm{L}^{-1}$ & $<2,19 \%>2(31)$ & $<2,31 \%>2(13)$ & $<2,36 \%>2(14)$ & $<2,33 \%>2(27)$ & 0.65 & 0.48 \\
\hline \multicolumn{7}{|l|}{ Inflammatory markers in sputum } \\
\hline Macrophages $\times 10^{6}$ cells $\cdot g^{-1}$ & $0.22(31)$ & $0.30(13)$ & $0.16(14)$ & $0.22(27)$ & 0.98 & 0.49 \\
\hline Total cells $\times 10^{6}$ cells $\cdot g^{-1}$ & $0.42(31)$ & $0.64(13)$ & $0.31(14)$ & $0.44(27)$ & 0.77 & 0.59 \\
\hline Interleukin-8 ${ }^{\bullet} \mathrm{ng} \cdot \mathrm{g}^{-1}$ & $6.5(31)$ & $5.1(13)$ & $5.6(14)$ & $5.6(27)$ & 0.61 & 0.75 \\
\hline Myeloperoxidase $n g \cdot g^{-1}$ & $0,19 \%>0(31)$ & $0,38 \%>0(13)$ & $0,36 \%>0(14)$ & $0,37 \%>0(27)$ & 0.15 & 0.36 \\
\hline TNF- $\alpha p g \cdot g^{-1}$ & $1.74(28)$ & $1.68(12)$ & $2.07(13)$ & $1.87(25)$ & 0.80 & 0.87 \\
\hline MMP-9 $\mathrm{ng} \cdot \mathrm{g}^{-1}$ & $236(24)$ & $244(10)$ & $284(13)$ & $266(23)$ & 0.84 & 0.67 \\
\hline$\alpha_{2}$-Macroglobulin $\mu \mathrm{g} \cdot \mathrm{mL}^{-1}$ & $164(23)$ & $160(11)$ & $223(13)$ & $193(24)$ & 0.78 & 0.53 \\
\hline \multicolumn{7}{|l|}{ Immunological markers } \\
\hline Pneumococcal $\lg \mathrm{G}$ antibodies $\mu \cdot \mathrm{mL}^{-1}$ & $60(31)$ & $108(13)$ & $63(13)$ & $83(26)$ & 0.24 & 0.44 \\
\hline Neutrophil fluorescence \% & $72(31)$ & $68(13)$ & $67(14)$ & $68(27)$ & 0.17 & 0.23 \\
\hline Neutrophil intensity & $115(31)$ & $124(13)$ & $142(14)$ & $132(27)$ & 0.18 & 0.12 \\
\hline $\operatorname{lgA}$ in sputum $\mu \mathrm{g} \cdot \mathrm{mL}^{-1}$ & $9.7(25)$ & $11.6(11)$ & $14.5(12)$ & $13.0(23)$ & 0.36 & 0.21 \\
\hline
\end{tabular}

Data are presented as the mean (n), back transformed to original scale where appropriate, unless otherwise indicated. TNF: tumour necrosis factor; MMP: matrix metalloproteinase; Ig: immunoglobulin. ${ }^{*}$ : adjusting for age, average weekly alcohol consumption and smoking status (in three bands); ": data presented as the median (n).

welders' sputum did not differ significantly from that in nonwelders.

When welders were subclassified according to the frequency of welding in a typical week or number of years spent as a welder (table 3), instead of by iron concentration in the sputum, then essentially similar results were obtained. Significantly higher levels of iron were again found in sputum and in cellular residue, and significantly lower levels of UIBC. There were small nonsignificant differences in blood basophil and eosinophil counts and a marginally higher level of pneumococcal antibodies in long-term welders $(\mathrm{p}=0.09)$.

Only one welder had a past history of pneumonia since first welding. There were no striking differences in the levels of inflammatory mediators in this individual relative to other welders or controls.

\section{DISCUSSION}

Welders in the present study had sufficient exposure to metal fume to result in significantly higher levels of iron and significantly lower levels of UIBC in their sputum, and were in other ways comparable to the metal-fume exposed populations in whom excesses of pneumonia have been previously demonstrated. However, despite this, few meaningful differences were detected in biological indices of host defence or inflammation in their blood and sputum relative to controls.

The present authors employed two surrogates to confirm and subclassify the extent of exposure, i.e. biomarkers of iron uptake and exposure history. The current authors consider the former of these two proxys to be a more reliable index, as work patterns may vary and intensity of welding may differ, as may the control measures employed. Moreover, recall and selfreporting of time-varying exposures is challenging and 
TABLE 3 Comparison of inflammatory and immunological measures according to frequency and intensity of welding

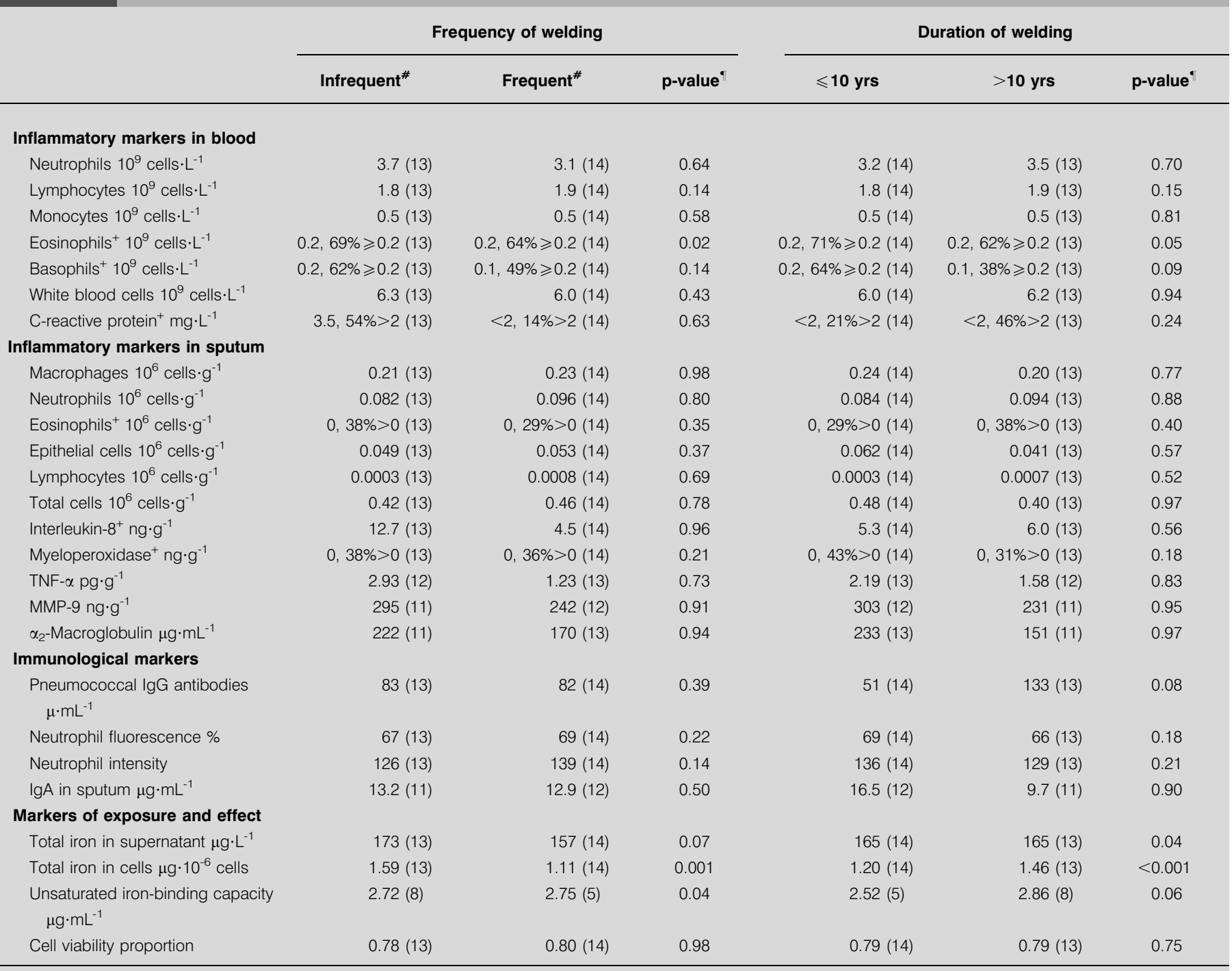

Data are presented as mean $(\mathrm{n})$, back transformed to original scale where appropriate, unless otherwise indicated. TNF: tumour necrosis factor; MMP: matrix metalloproteinase; Ig: immunoglobulin. ${ }^{*}$ : frequent defined as welding for $\geqslant 3$ days $^{\text {week }}{ }^{-1}$ in an average working week, and for $>2 \mathrm{~h}$ on welding days; " adjusting for age, average weekly alcohol consumption and smoking status (in three bands; the test of trend takes, as its baseline, the values in nonwelders presented in table 2); + : data presented as median (n).

sometimes leads to inconsistencies (the present authors found an imperfect concordance between estimated extent of welding and level of iron in the lungs for several comparisons in table 3). Iron levels in the cellular residue are also more likely to represent exposures over the past few months, the time period for which there is epidemiological support for an elevated risk of pneumonia [15, 16]. However, whether welders were subclassified by biomarkers of iron uptake or by intensity or duration of welding in the present study, little evidence was found of a generalised inflammatory response or impaired immunity, even amongst those who were most exposed.

Low levels of serum UIBC have been linked with high fatality from pneumococcal pneumonia [30], but risk by levels of UIBC in the airways remains essentially unexplored. Dose-related decrements in sputum UIBC were found in the welders. Whether or not free iron was present at a high enough level in the extracellular milieu to act directly as a growth nutrient, as previously theorised [18], is unclear.

Only a few differences were detected in other parameters. The raised level of basophils and eosinophils in blood could have arisen from an allergic response to metal fume, but the welders had no symptoms suggestive of asthma and no corresponding increase in these cellular elements was observed in the airways. Another possibility is that inhaled particulates induced epithelial damage, or activated alveolar macrophages to establish a systemic eosinophilia and basophilia through cytokine signalling [31]. The somewhat higher levels of CRP 
and evidence of low grade neutrophil activation in blood would be consistent with a weak effect of this kind.

However, in the airways, there was remarkably little evidence of a corresponding activation of cells or release of cytokines. $\alpha_{2}$-Macroglobulin levels tended to be higher, suggesting that inhaled metal fume induces plasma exudation. However, levels of MPO, a relatively specific marker of neutrophil activation, and of MMP-9 and TNF- $\alpha$, were only a little higher, and IL-8 levels in sputum only marginally lower, than in nonwelders.

These findings are at odds with the existing experimental data on lung responses to PM arising from environmental air pollution. Metal-rich PM from urban air normally induces a release of pro-inflammatory mediators (including TNF- $\alpha$ and IL-8) when incubated with human bronchial epithelium or alveolar macrophages [20,21]. Similar responses have been found in the airways of healthy subjects exposed to diesel exhaust [22]. The in vitro response to residual oil fly ash, a model for iron-rich PM, can be abolished by incubation with the iron chelator desferrioxamine [21], and it has been hypothesised that air pollution exerts its inflammatory effect via oxidative stress, catalysed by metals present in PM. Certain other occupational particulates, such as zinc oxide in metal fume fever [32] and dust from coal mines [33], have also been linked with release of cytokines and influx into the airways of inflammatory cells.

In this context, the absence of an apparent effect on biological indices of host defence in welders with significant lung burdens of iron is noteworthy and, indeed, an unexpected finding. It is unlikely to have arisen from insufficient exposure, or from inadequate technique. The methods used for sputum induction, processing and measurement of fluid phase mediators have been standardised and are well established [27]. Although sputum induction samples are obtained mainly from the bronchi, while the excess risk of lobar pneumonia suggests an alveolar mechanism, there is empirical evidence that bronchoalveolar lavage and sputum induction produce qualitatively and quantitatively similar results in workers exposed to particulates [34].

Susceptible welders with recurrent episodes of pneumonia could have been selected out of the workforce, but the current authors consider this to be unlikely (pneumonia would be considered a rare occurrence in this working population). In addition, the present study sample of volunteers could have been healthier than welders as a whole. However, a "healthy worker" effect cannot readily explain the absence of an expected response to a particulate load (a healthier workforce would, if anything, mimic the general population more closely in reacting to inhaled PM). Nearly all of the welders had recent exposures (within $48 \mathrm{~h}$ of testing) and welding fume can cause acute irritation, but again this would tend to make the response in welders different from controls, and therefore does not account for the similarity that was found. Another possibility is that positive findings were missed by chance because of the sample size, or through a failure to measure the parameters that matter most in promoting pneumonia (a selection was made from among the more plausible candidates). However, diesel exhaust has been reported previously to induce leukocytic infiltration of the airways and raised IL-8 levels in bronchial washings from a smaller sample of subjects than reported here [22, 35], and the current authors' failure to observe any substantial differences in cellular and cytokine response is therefore striking. It is possible that iron-containing metal fume is simply not a potent stimulant of airways, despite some suggestive contrary experimental observations [20-22], but, if so, the reason for this needs to be more fully understood.

The absence of a local response and the existence of a modest systemic reaction may arise if homeostatic mechanisms diminish the local reaction to metal fume. However, it is hard to reconcile this with the response of normal human lung tissue to air pollutants bearing much less iron [35].

A more appealing hypothesis is that excessive iron impairs the normal capacity to respond to inhaled PM and the effect is such as to augment infective risk. In keeping with this idea is some recent experimental evidence that urban air pollution impairs clearance of Streptococcus pneumoniae in rats through an iron-dependent mechanism that manifests as a muted capacity to recruit polymorphs and produce ILs and TNF- $\alpha[36,37]$. A muted response to inhaled particulate is also suggested by the differential response to cigarette smoke in the presented subjects. Although based upon small numbers and of borderline statistical significance, higher levels of MMP-9, IgA and $\alpha_{2^{-}}$ macroglobulin were observed in smokers compared with nonsmokers when analysis was confined to nonwelders, but no such differences were found for welders.

It is conceivable that the unusually high burden of transitional metal in welders' lungs could promote apoptosis via ironcatalysed oxidative stress, impairing the activation of neutrophils or other cellular elements in the airways [23, 24]. Streptococcus pneumoniae (the organism most clearly identified with infective risk from exposure to metal fume [16]) can promote apoptosis to enhance its own pathogenicity [38], and apoptosis has been induced experimentally by inorganic iron in human endothelium [39]. Such a process could render welders more vulnerable to infection, and a short-term reversible increase in risk of infection (the pattern suggested by epidemiological evidence) could last until exposure ceases, free iron is safely stored and apoptotic cells are replaced with healthy ones. The proportion of viable cells measured by exclusion of trypan blue in welders lungs did not differ significantly from that in nonwelders, which tends not to support this hypothesis. However, during apoptosis the neutrophil surface membrane remains intact and continues to exclude vital dyes. Thus, apoptotic events precede cell death, which can in any case have other causes, and since no staining or biochemical analysis was undertaken to measure apoptosis in the present study (and no in vitro tests of cellular stimulation in sputum), the authors cannot confidently reject the possibility.

The increased risk of pneumonia in welders is not yet explained. However, an absence of the expected local inflammatory response to particulate matter provides some encouragement to explore the role of free radical injury and apoptotic cell death in further targeted research. Another sensible step would be to measure directly markers of oxidative activity, such as malondialdehyde and lipid hydroperoxides in 
welders' sputum and to test the function in vitro of alveolar macrophages and neutrophils from welders' lungs. Finally, if chronic exposure to ferrous fume blunts the response to particulate matter, a difference in inflammatory responsiveness should be evident between long-term welders and naive but acutely exposed subjects, and this would be worth establishing as a first priority.

\section{ACKNOWLEDGEMENTS}

The authors would like to thank C. Harris (MRC), J. Ward and the laboratory staff at Southampton General Hospital (Southampton, UK), and L. Marshall, M. Nash and S. Clarke (School of Pharmacy and Biomedical Sciences, University of Portsmouth, Portsmouth, UK). The authors would also like to thank J. Henderson, W. Fowler and the occupational health staff of HM Naval Base, Portsmouth, and P. McIntosh, B. Hicks, B. Irvine and K. Parry (Fleet Support Ltd, Portsmouth, UK) and the 58 volunteers from Fleet Support Ltd's staff.

\section{REFERENCES}

1 Office of Population Censuses and Surveys. Hospital Inpatient Enquiry 1985. London, HMSO, 1985; Series MB4.

2 Everett MT. Major chest infection managed at home. The Practitioner 1983; 227: 1743-1754.

3 Woodhead MA, MacFarlane JT, McCracken JS, Rose DH, Finch RG. Prospective study of the aetiology and outcome of pneumonia in the community. Lancet 1987; i: 671-674.

4 MacFarlane JT, Finch RG, Ward MJ, Macrae AD. Hospital study of adult community acquired pneumonia. Lancet 1982; 2: 255-258.

5 Sullivan RJ, Dowdle WR, Marine WM, Hierholzer JC. Adult pneumonia in a general hospital. Arch Intern Med 1972; 29: 935-942.

6 Harrison BDW, Farr BM, Pugh S, Selkon JB, Prescott RJ, Connolly CK. Community-acquired pneumonia in adults in British hospitals in 1982-1983: A survey of aetiology, mortality, prognostic factors and outcome. Q J Med 1987; 62: 195-220.

7 Ferandez-Sola J, Junque A, Estruch R, Monforte R, Torres A, Urbano-Marquez A. High alcohol intake as a risk and prognostic factor for community-acquired pneumonia. Arch Int Med 1995; 155: 1649-1654.

8 Ferguson A. Hazards of hyposplenism. BMJ 1982; 285: 1375.

9 Nuorti JP, Butler JC, Farley MM, et al. Cigarette smoking and invasive pneumococcal disease. N Engl J Med 2000; 342: 681-689.

10 Stark JE. Parenchymal lung diseases: infections of the respiratory tract. In: Weatherall DW, Ledingham JGG, Warrell DA, eds. Oxford Textbook of Medicine. Oxford, Oxford University Press, 1984; pp. 15.73-15.75.

11 Hodges RG, MacLeod CM. Epidemic pneumococcal pneumonia. V. Final observations of the factors underlying the epidemic. Am J Hyg 1946; 44: 237.

12 Registrar General. Decennial Supplement England and Wales 1951. London, HMSO, 1958; Occupational Mortality part II, vol 1.

13 Registrar General. Decennial Supplement England and Wales 1961. London, HMSO, 1971; Occupational Mortality Tables.
14 Registrar General. Decennial Supplement England and Wales 1971. London, HMSO, 1981; Series DS no 1.

15 Coggon D, Inskip $H$, Winter $\mathrm{P}$, Pannett B. Lobar pneumonia: an occupational disease in welders. Lancet 1994; 344: 41-44.

16 Palmer KT, Poole J, Ayres JG, Mann J, Burge PS, Coggon D. Exposure to metal fume and infectious pneumonia. Am J Epidemiol 2003; 157: 227-233.

17 Antonini JM. Health effects of welding. Crit Rev Toxicol 2003; 33: 61-103.

18 Palmer K, Coggon D. Does occupational exposure to iron promote infection? Occup Environ Med 1997; 54: 529-534.

19 Brandtzaeg P. The role of humoral immunity in the induction and maintenance of chronic airway infections. Am J Respir Crit Care Med 1995; 151: 2081-2086.

20 Ulrich MM, Alink GM, Kumarathasan P, Vincent R, Boere AJ, Cassee FR. Health effects and time course of particulate matter on the cardiopulmonary system in rats with lung inflammation. J Toxicol Environ Health 2002; $65 \mathrm{Pt}$ A: $1571-1595$.

21 Carter JD, Ghio AJ, Samet JM, Devlin RB. Cytokine production by human airway epithelial cells after exposure to air pollution particle is metal-dependent. Toxicol Appl Pharmacol 1997; 146: 180-188.

22 Salvi SS, Nordenhall C, Bloomberg A, et al. Acute exposure to diesel exhaust increases IL- 8 and GRO- $\alpha$ production in healthy human airways. Am J Respir Crit Care Med 2000; 161: 550-557.

23 Mecklenburgh KI, Walmsley SR, Cowburn AS, et al. Involvement of a ferroprotein sensor in hypoxia-mediated inhibition of neutrophil apoptosis. Blood 2002; 100: 3008-3016.

24 Polla BS. Therapy by taking away: the case of iron. Biochem Pharmacol 1999; 57: 1345-1349.

25 Rollet-Labelle E, Grange M-J, Elbim C, Marquetty C, Gougerot-Pocidalo M-A, Pasquier C. Hydroxyl radical as a potential intracellular mediator of polymorphonuclear neutrophil apoptosis. Free Radic Biol Med 1998; 24: 563-572.

26 Duque RE, Ward PA. Quantitative assessment of neutrophil function by flow cytometry. Anal Quant Cytol Histol 1987; 9: 42-48.

27 Djukanovic R, Sterk PJ, Fahy JV, Hargreave FE. Standardised methodology of sputum induction and processing. Eur Respir J 2002; 20: Suppl. 37, 1s-2s.

28 Louis R, Shute J, Biagi S, et al. Cell infiltration, ICAM-1 expression, and eosinophil chemotactic activity in asthmatic sputum. Am J Respir Crit Care Med 1997; 155: 466-472.

29 Kleiner DE, Stetler-Stevenson WG. Quantitative zymography: detection of picogram quantities of gelatinises. Anal Biochem 1994; 218: 325-329.

30 Lambert CC, Hunter RL. Low levels of unsaturated transferrin as a predictor of survival in pneumococcal pneumonia. Ann Clin Lab Sci 1990; 20: 140-146.

31 Fujii T, Hayashi S, Hogg JC, et al. Interaction of alveolar macrophages and airway epithelial cells following exposure to particulate matter produces mediators that stimulate the bone marrow. Am J Resp Cell Mol Biol 2002; 27: 34-41.

32 Blanc P, Wong H, Bernstein MS, Boushey HA. An experimental model of metal fume fever. Ann Int Med 1991; 114: 930-936. 
33 Vallyathan V, Goins M, Lapp LN, et al. Changes in bronchioalveloar lavage indices associated with radiographic classification in coal miners. Am J Respir Crit Care Med 2000; 162: 958-965.

34 Fireman E, Grief J, Schwarz Y, et al. Assessment of hazardous dust exposure by BAL and induced sputum. Chest 1999; 115: 1720-1728.

35 Salvi S, Bloomberg A, Rudell B, et al. Acute inflammatory responses in the airways and peripheral blood after shortterm exposure to diesel exhaust in healthy human volunteers. Am J Respir Crit Care Med 1999; 159: 702-709.

36 Zelikoff JT, Chen LC, Cohen MD, et al. Effects of inhaled ambient particulate matter on pulmonary antimicrobial immune defence. Inhal Toxicol 2003; 15: 131-150.
37 Zelikoff JT, Kimberly R, Schermerhorn R, Fang K, Cohen MD, Schlesinger RB. A role for associated transition metals in the immunotoxicity of inhaled ambient particulate matter. Environ Health Perspect 2002; 110: 871-875.

38 Hakansson A, Carlstedt I, Davies J, Mossberg AK, Sabharwal H, Svanborg C. Aspects on the interaction of Streptococcus pneumoniae and Haemophilus infleunzae with human respiratory tract mucosa. Am J Respir Crit Care Med 1996; 154: Suppl. 4 Pt 2, S184-S191.

39 Jacob AK, Hotchkiss RS, DeMeester SL, et al. Endothelial cell apoptosis is accelerated by inorganic iron and heat via an oxygen radical dependent mechanism. Surgery 1997; 122: 243-253. 